\title{
Use of a MOOC Platform to Blend a Linear Circuits Course for Non-Majors
}

\section{Dr. Bonnie H. Ferri, Georgia Institute of Technology}

Dr. Bonnie Ferri is a Professor and the Associate Chair for Undergraduate Affairs in the School of Electrical and Computer Engineering at Georgia Tech. She performs research in the area of active learning, embedded computing, and hands-on education. She received the IEEE Education Society Harriet B. Rigas Award.

Dr. David Michael Majerich, Century for 21st Century Universities

Mr. Nathan VerDon Parrish, Georgia Institute of Technology

Prof. Aldo A. Ferri, Georgia Institute of Technology

Al Ferri received his BS degree in Mechanical Engineering from Lehigh University in 1981 and his PhD degree in Mechanical and Aerospace Engineering from Princeton University in 1985. Since 1985, he has been a faculty member in the School of Mechanical Engineering at Georgia Tech, where he now serves as the Associate Chair for Undergraduate Studies. His research areas are in the fields of dynamics, controls, vibrations, and acoustics. He is also active in course and curriculum development. He is a Fellow of the ASME. 


\title{
Use of a MOOC Platform to Blend a Linear Circuits Course for Non-Majors
}

\begin{abstract}
:
This paper describes a project where a MOOC (Massive Open Online Course) was developed in order to blend a Circuits and Electronics course taught to non-majors at Georgia Tech. The MOOC platform contains videos of all the course lectures, online homework, and quizzes. Over 400 students take this course on campus each term. Since these students were spread over eight to nine sections, consistency of coverage and of grading was a major motivation for inverting this course. Another major motivation for the course inversion was to be able to introduce hands-on activities into the classroom so that students can get small-scale laboratory experiences within a lecture-based course. A number of different assessment methods are on-going with this course.
\end{abstract}

\section{Introduction}

Circuits courses for non-majors typically have some of the highest enrollments of any engineering course since they are required by so many majors. Viewed as "service courses" by both students and instructors, these courses are often taken grudgingly by students because they are required out-of-major courses and are often taught by adjunct instructors or Graduate Teaching Assistants. Thus, they are pedagogically a challenge to teach due to low student and instructor motivation levels.

The motivation for blending this course was to provide consistency across sections, allow for in-class hands-on activities, and to enhance other forms of collaborative and active learning. Consistency in coverage had been a problem with this particular course, which is taught every term and has 8-9 sections of 45-50 students each. The instructors are senior PhD students, many of whom are interested in academic careers. A survey of the instructors showed a large inconsistency in coverage, upwards of $20 \%$ mismatch in topics between sections. High levels of inconsistency across multiple sections of a course is not unusual even among experienced instructors when the syllabus is considered to be "packed with material." Blending the course with all course lectures online and common homework and exams across all sections removes most of the inconsistency across sections.

Another major motivation for inverting this particular course was to provide an opportunity to bring hands-on experimental activities into the classroom. Previous studies at Georgia Tech showed that the inclusion of mini labs done in a lecture-based course enhanced students' understanding of fundamental concepts in the course ${ }^{1-2}$. However, many professors limited the number of in-class activities citing the need to "get through" the lecture material. By providing online lectures to blend the Circuits and Electronics course for nonmajors, six experiments were added into the course all done during standard 50-minute lecture class periods. 
Why use a MOOC to invert a class? The MOOC platform, specifically Coursera, is complete learning environment. The main component is the set of online lectures, including the ability to add short in-video concept quizzes to keep students focused. In addition, it has an advanced learning management system including automatically graded quizzes and homework problems, a forum for questions, a calendar with staged emails to remind students of upcoming deadlines, and a structure to organize all of the course materials for ease of student navigation. The platform itself provides the needed infrastructure to invert a class; however, offering a MOOC is more challenging since the MOOC must be a self-contained course with assignments and quizzes. The MOOC establishes a baseline for students wanting an introduction to the field, and the higher levels of cognitive understanding and synthesis are strengthened from the in-class and face to face experience. From a scheduling and content standpoint, the MOOC establishes a pace through the material that does not fall prey to different types of delays and disruptions that often leads to inconsistency across sections. Different universities have experimented with MOOCs to support courses, but the most common usage is as supplemental resources.

Closely related to the work presented in this paper is the experiment performed on a similar Circuits Analysis class (EE98) at San Jose State University. In the fall of 2012, course material from edX's Circuits and Electronics MOOC (MITx 6.002x Circuits and Electronics, described more fully in various references ${ }^{3-4}$ ) was used to supplement the Circuits Analysis course at SJSU. Among the 3 sections of the course offered in Fall 2012, two sections were taught in the traditional format, and one section was "flipped" using MIT videos. As widely reported, the "passing rate" of the traditional sections was 57 and 74\%, while that of the flipped section was 95\%. In the spring of 2013, SJSU ran another set of 3 sections of their class; again, two sections were taught in traditional mode and one taught using edX content. However in that trial, all three sections followed the edX MOOC curriculum much more closely. It was reported that the pass rates in the spring were 79 and $82 \%$ for the traditional class and $87 \%$ for the experimental section ${ }^{5}$.

\section{Background on Blended Courses}

There has been considerable research on the development and efficacy of blended classes. The term "blended class" implies the use of two or more modes of delivery- most commonly traditional face-to-face classroom instruction and online, video content. Blended classes are also called "flipped classes," "inverted classes," or "hybrid classes," but there isn't a strong consensus among instructors about differences in these concepts, if any ${ }^{6}$.

According to a 2007 Sloan Consortium publication ${ }^{7}$, blended courses are ones that "combine the elements of an online course with those of face-to-face instruction." The Blended Learning Implementation Guide ${ }^{8}$ defines blended learning as "a formal educational program in which a student learns at least in part through the online delivery of content and instruction, with some element of student control over time, place, path, and pace, and at least in part at a supervised brick-and-mortar location away from home." While some view blended courses as a 
temporary state of existence as the course transitions from traditional mode to a fully-online mode, it is now widely recognized that blended classes are a deliberate implementation strategy, where the best attributes of face-to-face instruction and the best attributes of online learning are combined. Blended learning is perhaps best suited to STEM fields such as engineering, because engineering education is often characterized by classes that are dense in information delivery; classes are typified by the one-way delivery of content with little time or opportunity for discussion, questions, and collaboration.

In recent years, several papers have appeared documenting the development and performance of blended engineering courses. Papadopoulos and Roman ${ }^{9}$ described their experience with inverting an introductory statics class. They used Pre-lecture modules, Lectures, and Post-lecture problem-solving sessions. The pre-lecture modules were PowerPoint slides with Moodle exercises that students were required to watch prior to coming to class. The classroom activity consisted of a short review, followed by critical discussion, problem-solving activities, and answering students' questions. Assessment results presented by the author showed a slight improvement in learning for the inverted course delivery vs the traditional course delivery. The inverted classes were well received by the instructors and the students, however, some students indicated that the inverted class required more time than traditional version, perhaps due to the post-lecture problem-solving sessions. Morin, et al. ${ }^{10}$ implemented an inverted classroom in the delivery of a first-year engineering course. The study involved several instructors and several sections of the class, which had previously been taught entirely in a traditional lecture mode. In a set of identical test questions used in both offerings, it was found that student performance was about; i.e., "the change in approach did not have a negative impact on student learning." Mason, et al. ${ }^{11}$ described a senior-level controls class taught as an inverted or flipped class. The authors developed a series of online videos that enabled the movement of traditional lecture material outside the class time, thus leaving time in class for "learner-centered activities." The authors compared several aspects of the inverted class (IC) to a traditional class (TC.) As with the statics course discussed above, the learning gains reported by the authors were fairly similar between the IC and TC versions. The difficulties of controlling for time-on-task make it especially difficult to conclude that blended or inverted classes offer greater learning gains per unit of time than the traditional mode of delivery. Thus, if there are advantages to blended classes, they would seem to be centered on ancillary benefits such as the ability to access videos on demand, to control the pace of the lecture, and to replay portions of the video which they found to be particularly difficult.

A survey on inverted classes by Bishop and Verleger ${ }^{12}$ echoes many of the observations presented above. Citing 83 references plus another 38 online sources, the authors list many perceived advantages of flipped classes, including the ability to combine learning theories that are quite different; namely active, problem-based learning, and instructional lectures based on behaviorist principles. They report that student perceptions of flipped classrooms are "somewhat mixed, but generally positive overall." Learning outcomes, however, have not shown significantly positive results. In fact of all the references that they examined, only one ${ }^{13}$ showed 
significant improvement in scores on homework, projects, and tests, compared with traditional instruction. The authors strongly suggest that future research should be conducted, especially research that examines learning outcomes using controlled studies. The research reported herein attempts to supply this much needed assessment data.

The course was taught as a pilot to 130 on-campus students during the summer of 2013. Based on the feedback of the pilot group, the course was fine-tuned prior to offering it full-scale in Fall 2013. Over 16,000 students signed up for the open version of the course with approximately 3000 students active in the course on a weekly basis. This research is based on the modifications made to blended elements of the course (MOOC, in-class laboratory activities, in-class problem solving) from the pilot study and examines how students' conceptual understanding of circuits topics changed over seven weeks.

\section{Methodology}

\section{Description of Circuits and Electronics Course}

Circuits and Electronics is a 2 credit hour junior-level course that is 15 weeks long. Eight weeks is spent covering linear circuits topics and six weeks is devoted to electronics. The prerequisite for the course is Physics 2 (Circuits and Electromagnetics). The major topics include

- Resistive Networks (including Kirchoff's Laws and DC circuit analysis using Mesh, Node, and Thévenin's Theorem)

- Reactive Circuits (capacitors and inductors and transient response of first-order circuits and series RLC circuits)

- Frequency Response (AC analysis, frequency response, Bode plots, filters)

- AC Power Analysis (real power, reactive power, power factor)

- Op Amps (ideal behavior, basic resistive circuits, basic first-order filters)

- Diodes (ideal behavior, rectifiers)

- Transistors (MOSFETs in logic gates and simple amplifiers)

There is a large breadth of coverage, and it is challenging to go through the material at a level appropriate for a 2 credit hour course. Having the course be very structured with predefined lectures, good organization, and standard due dates for deliverables helps to ensure the appropriate coverage and pace.

The course is required by majors in mechanical engineering, aerospace engineering, and materials science. A significant number of other majors take it as an elective. A total of 950-1000 students are enrolled in the course each year. Prior to the current MOOC-enhanced offering, the course was taught by graduate students across eight to nine sections of 50 students each. The instructors varied in the depth that they gave to topics in the course and very few of them covered all the required topics. A survey of the students showed the there was a mismatch of up to $25 \%$ of topics across the sections, that is, different instructors dropped different portions of the course for lack of time. The choices to remedy the inconsistency across sections were to 1) offer 
a large lecture section with recitations, 2) record the lectures and invert the classroom, 3) have more experienced professors teach the sections. Option 3 was expensive and did not guarantee consistency. Option 2 was chosen since inverting the classroom made time in class for engaging students in hands-on activities that supported the methods learned in the lectures.

A MOOC platform was selected to facilitate this option because of its advanced learning management system. It serves a dual purpose: to provide a free online course and to provide a means to invert the Circuits and Electronics course.

Two MOOCs are intended to cover all the material for this on-campus course. The first is Linear Circuits and covers the topics listed above from Resistive Networks to AC Power Analysis. The second MOOC, under development, is Introduction to Electronics covering the topics from op amps to transistors. The focus of this paper is the incorporation of the Linear Circuits MOOC into the Circuits and Electronics course.

This particular on-campus course and associated MOOCs are integrally tied together. Both sets of audiences have the same lectures, homework, quizzes, and share the same forum. There were two almost duplicate simultaneous instances of the MOOC, one for the general offcampus students and one strictly for on-campus students so that we could track their grades and send out separate announcements to them. Figure 1 shows a screen shot of the Coursera main page for the course. Notice that the site gives a navigation panel on the left and a schedule of upcoming deadline on the right. The functionality provided by the Coursera system allows one to organize all facets of the course in a manner that would be difficult to do otherwise. The video players allows students to view the video in speeds from $0.75 \mathrm{x}$ to $2 \mathrm{x}$ normal speed, thereby adapting to individual student preferences. The videos for this course use in-video quizzes to embed formative assessment into the lectures. These quizzes are very simple and are targeted to the basic concepts being covered. In the lower part of the navigation bar on the left in Figure 1 is a link to the Forum, which uses Piazza. A common forum is used for both the on-campus students and the public MOOC students. The shared forum was visited by both the online and the on-campus students, with some of the on-campus students patiently answering many questions as if they were unpaid teaching assistants.

The main difference between the online course and the on-campus course is the face-toface interactions in the classroom. It should be mentioned that part of that live experience is hands-on activities done with student-owned National Instruments myDAQ measurement devices. The on-campus students have 6 experiments that are performed during a regular class period, ranging from a measurement of resistor combinations to building a full-wave rectifier. These experiments are meant to support the online lecture material rather than to introduce additional topics. Demonstrations of physical circuit phenomena using a myDAQ are embedded into the lectures. These in-class lab instructions are provided to the public MOOC students as an option from the link in the navigation bar in Figure 1. The MOOC students were able to purchase the device at standard student discounts. 
Figure 1. Screen shot of the Linear Circuits MOOC main page for students

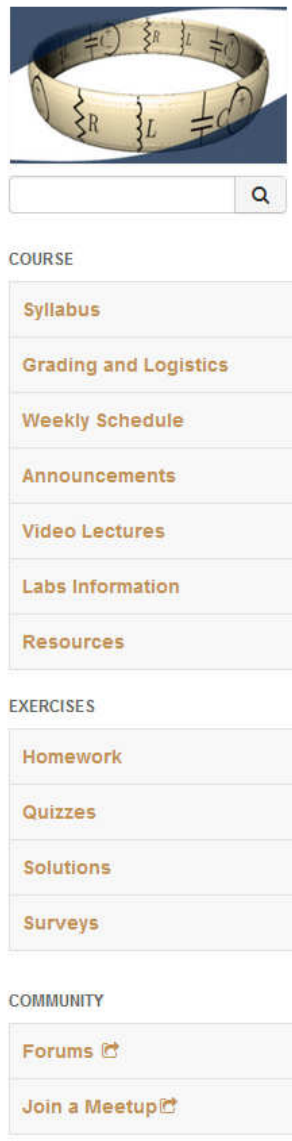

Announcements

Weekly Schedule for Week 1

Hi everyone.

The Week 1 schedule on the Weekly Schedule url is currently not opening up due to technical issues. Week 1 Module 1 details can be found on the Resources tab of the course page(https://class. coursera org/circuits-003/wiki/Resources)

The technical issue with the Weekly Schedule url's will be fixed soon

Thanks,

Prabha

Mon 6 Jan 2014 4:15 PM EST

\section{Week 1 Linear Circuits}

Week 1 starts Module 1 on Background Material. All lectures and homework problems have been posted are and visible from the links in the menu on the left. Look at the weekly schedule for details.

The homework for Week 1 is due next Sunday and the quiz for Module 1 is due the following Thursday. Week 2 materials have been posted for those of you who are ambitious.

Please make sure that you do the Beginning of the Course Survey. We really appreciate the feedback

Mon 6 Jan 2014 12:01 AM EST

\section{Linear Circuits Has Started}

The course is live now and you are welcome to start your activities for the class. Please look at the menu on the left of the course home page. Things to examine now:

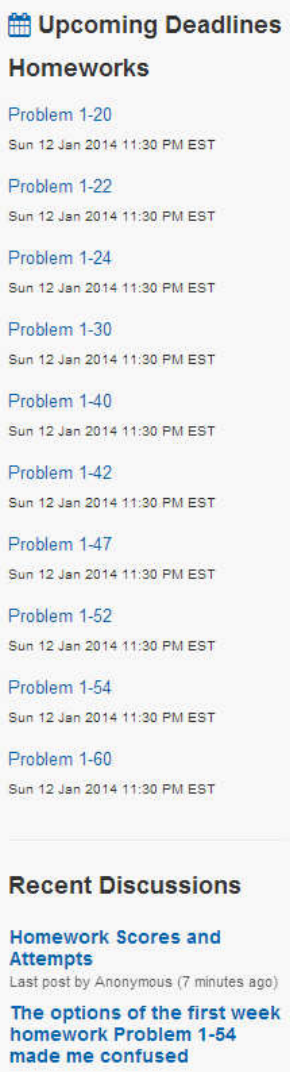

The grading structure for the on-campus students consists of the MOOC grade (homework and quizzes), in-class tests common across all sections, in-class labs, and in-class quizzes that are based on the online lectures. These short two-minute in-class quizzes provide a safeguard to making sure that students are keeping up with the material. The quizzes have been offered in a both an individual and collaborative manner. In addition to the six in-class labs during the term, the class time is devoted to questions that students have on the lecture material or homework material, working extra problems similar to the homework, and working on homework. Over the course of the semester students completed two mid-term exams and one final exam. The midterm exams and the final exam consisted of analysis problems and multiple choice problems. The final exam was comprehensive and included course material from the MOOC and the electronics portion of the course. Exams were designed collaboratively by the nine-member instructional team to identify which topics should be assessed in each exam.

\section{Subjects}

A total of 406 students enrolled in the blended Circuits and Electronics course to fulfill a major requirement or an elective requirement. Nine sections of the course were offered. From those who enrolled in the course, only 286 gave their consent to participate in this study. The 
sections and number of students per section were: Section $1(N=38)$, Section $2(N=23)$, Section 3 $(N=31)$, Section $4(N=40)$, Section $5(N=36)$, Section $6(N=39)$, Section $7(N=18)$, Section 8 $(N=34)$, and Section $9(N=27)$. Each section was taught by a different instructor.

\section{Methods}

The research approach uses a pretest-posttest design. Quantitative data were obtained from nine different sections of the Circuits and Electronics course. Each section met twice a week for 50-minute periods and each section was taught by a different instructor. The data source was a concept inventory administered at the beginning of the semester and again at the end of the semester.

Circuits Concept Inventory $(\boldsymbol{C C I})$ The $\mathrm{CCI}^{14}$ is a test that can be used to measure students' conceptual understanding of circuits topics, diagnose students' difficulty prior to instruction, and evaluate changes in students' conceptual understanding related to an intervention when used as a pre- and posttest. This test version has 25 items and uses a multiple choice response format where students select the best answer when given four answer choices. In this present study, three additional items were amended to the CCI for topics covered in the course that were not part of the original inventory. To be consistent with the original concept inventory, the amended items were each designed with four answer choices. Our 28 item inventory was administered during weeks 1 and 7 as a pretest and posttest, respectively. The pretest scores were also used to establish that the nine sections of students were equivalent (i.e., all sections of students started the course with the same level of prior knowledge about circuits). Since a modification to the original test was made, Cronbach's alpha $(\alpha=.76)$ was determined for the coefficient of internal consistency of items. A value of 0.70 to 0.90 is considered to represent good internal consistency of test items.

\section{Findings}

\section{Equivalent Groups}

In order to establish that the sections of students were equivalent in their understanding of circuits topics at the beginning of the semester, we examined the CCI pretest scores. Maximum possible points for the CCI pretest were 28 points. Correct answers were given a value of 1 for being correct and 0 for being incorrect. Total points were determined for each student and then converted to percentages. Results are presented as a bar-and-whisker chart that contains the CCI pretest mean scores and standard deviations for each of the nine sections of the course (Figure 2).

For the purpose of interpreting the chart, the height of the bar represents the mean score and the whisker represents one standard deviation on either side of the mean. The results are represented graphically and show how each section performed on the CCI pretest. We offer the bar-and-whisker chart for those who may be interested in seeing the performance of each section described with means and standard deviations. However, one of the main reasons for conducting this research was to determine how well each section did when compared to the other sections. In order to accomplish this, we utilize other techniques to analyze and describe our data. 
Figure 2. Means and standard deviations for the CCI pretest by course section, $1(N=38) ; 2(N=23) ; 3(N=31) ; 4(N=40) ; 5(N=36) ; 6(N=39) ; 7(N=18) ; 8(N=34) ; 9(N=27)$

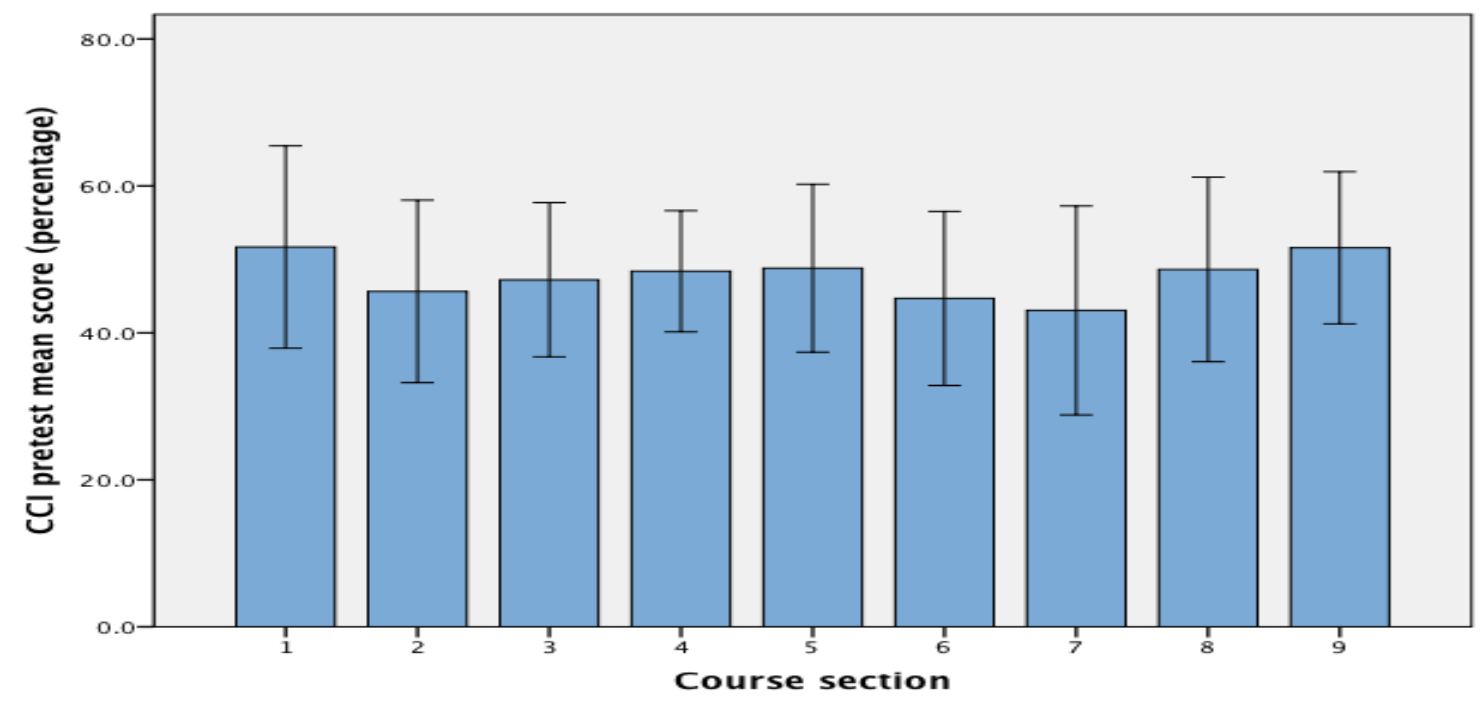

The one-way ANOVA is a parametric test that is commonly used to compare the means of three or more independent samples ${ }^{15}$. However, we have taken into account the differentially unequal samples sizes across the sections, and that student scores were not normally distributed within sections (i.e., our examination of the standardized skewness coefficient and kurtosis coefficient revealed severe departures from normality based on the criteria described by Onwuegbuzie and Daniel $^{16}$. In other words, our data violated the assumptions necessary for using the ANOVA statistical test ${ }^{17}$. Instead, we selected the non-parametric Kruskal-Wallis $H$ test to determine whether our groups (course sections of students) were different by comparing their respective medians. This nonparametric test is applied to ranked data ${ }^{18}$. In brief, each test score is associated with a rank where the smallest score is assigned a rank of 1 , the next smallest is assigned a rank of 2 , and so on. Tied scores are assigned an average rank. For instance, if two identical scores occupying the third and fourth smallest places when ranked, each would both be assigned an average rank of 3.5. The Kruskal-Wallis $H$ test was used to examine the data in this study. The details for the continued use of nonparametic tests also hold for our remaining analyses.

After we shifted our analysis from the CCI pretest means to the CCI pretest medians, we used the box-and-whisker plot to graphically show the distribution of scores for each section. The box-and-whisker plot describes the data in terms of: 1) median; 2) upper quartile; 3) lower quartile; 4) maximum score; 5) minimum score; and 6) outliers (out of the ordinary values, denoted by circles or asterisks). This technique is useful for describing the data without having to list all of the enumerated descriptive statistics. The bar-and-whisker charts and the box-andwhisker plots were also included for subsequent analyses because they are complementary ways to describe the data without using tables with numerical values. Figure 3 contains the box-andwhisker plot for the CCI pretest scores for each section. 
Figure 3. Box-and-whisker plot for the CCI pretest scores by course section, $1(N=38) ; 2(N=23) ; 3(N=31) ; 4(N=40) ; 5(N=36) ; 6(N=39) ; 7(N=18) ; 8(N=34) ; 9(N=27)$

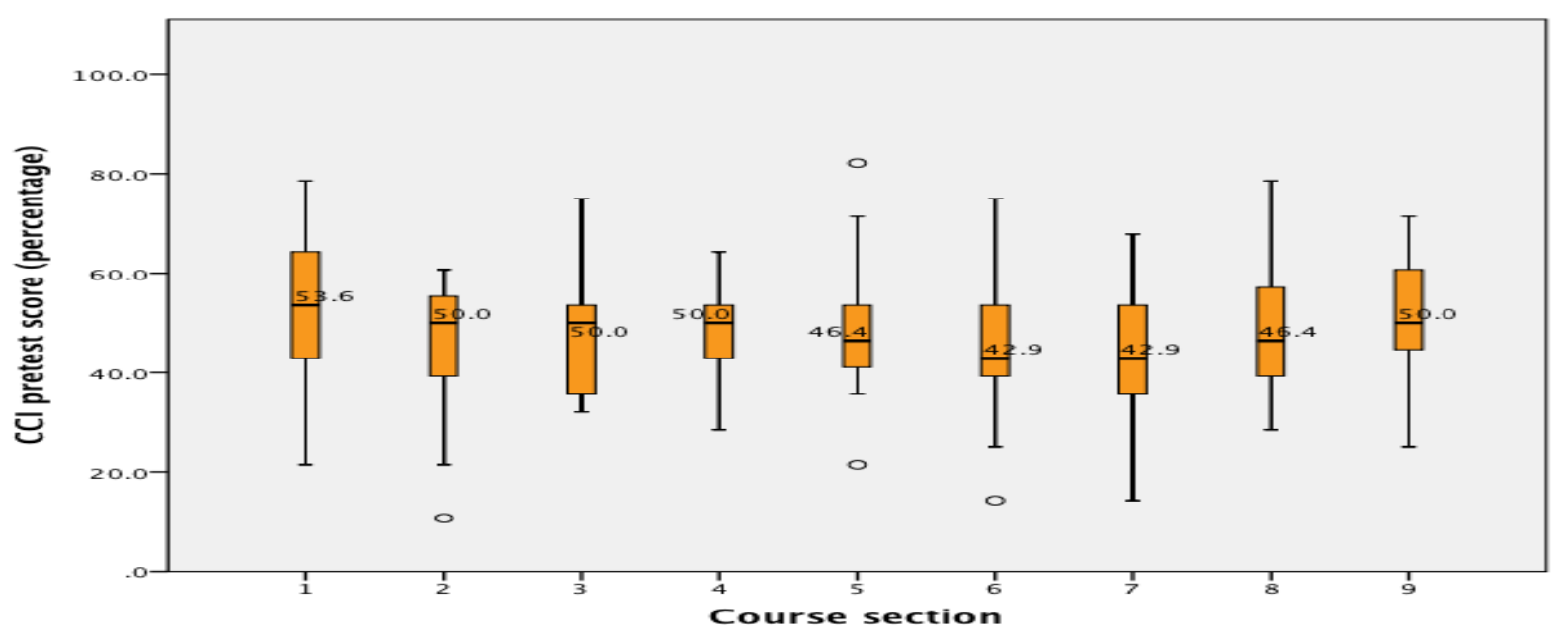

$\mathrm{o}=$ outlier that is out of the ordinary value

The graphical representation of data revealed the differences among the groups, but the data required further examination. The Kruskal-Wallis $H$ test was conducted to evaluate if there were differences in medians among the nine sections. The test, which was corrected for tied ranks, was not significant, $H(8, N=286)=13.106, p=.108$. Based on this result, the sections were equivalent with respect to their pre-course understanding of circuits concepts.

\section{Circiuits Concept Inventory (posttest)}

As for the CCI pretest, the maximum points for the CCI posttest was 28 points. Percentage scores were determined for each student as reported in this section for the CCI pretest. Figure 4 shows the CCI posttest means and standards deviations for each of the nine sections. After we shifted our analysis from the CCI posttest means to the CCI posttest medians, we used the box-and-whisker plot to graphically show the distribution of scores for each section. Figure 5 contains the box-and-whisker plot for the CCI posttest scores for each section.

The graphical representation of data revealed the differences among the groups, but the data required further examination. The Kruskal-Wallis $H$ test was conducted to evaluate if there were differences in medians among the nine sections. The test, which was corrected for tied ranks, was not significant, $H(8, N=286)=14.218, p=.076$. Based on this result, the sections were equivalent with respect to their post-MOOC understanding of circuits concepts measured during week 7 of the semester. 
Figure 4. Means and standard deviations for the CCI posttest by course section, $1(N=38) ; 2(N=23) ; 3(N=31) ; 4(N=40) ; 5(N=36) ; 6(N=39) ; 7(N=18) ; 8(N=34) ; 9(N=27)$

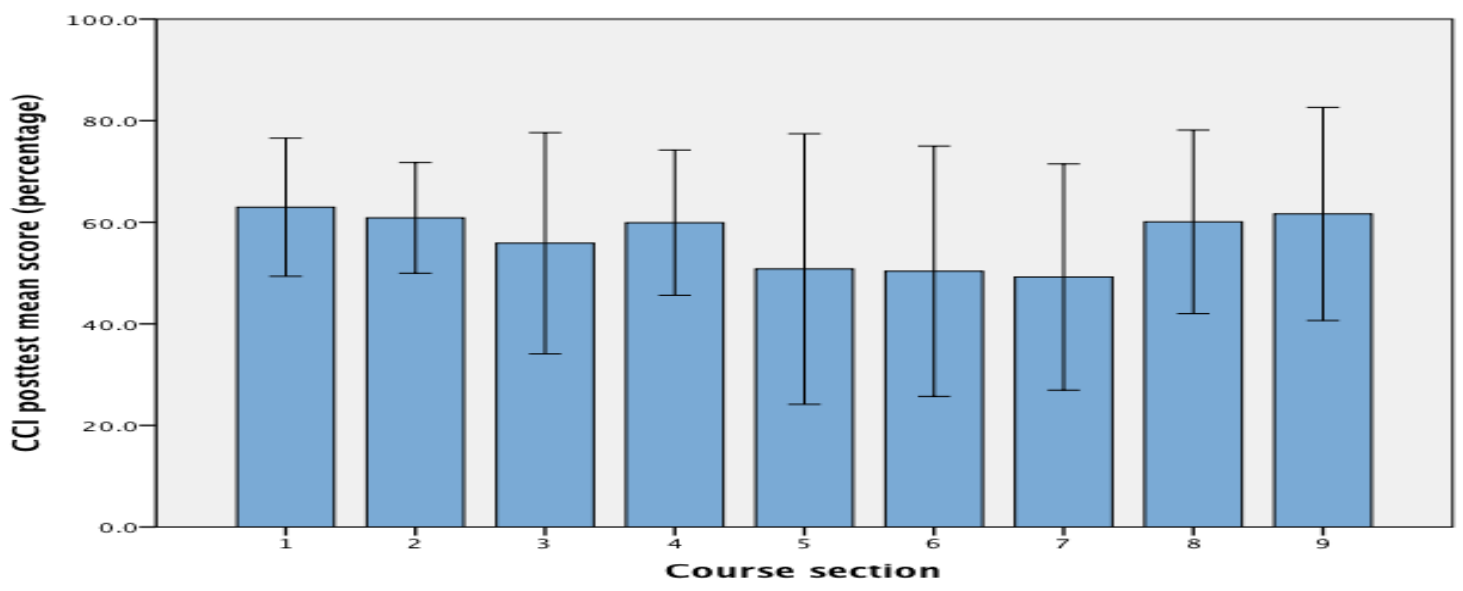

Figure 5. Box-and-whisker plot for the CCI posttest scores by course section, $1(N=38) ; 2(N=23) ; 3(N=31) ; 4(N=40) ; 5(N=36) ; 6(N=39) ; 7(N=18) ; 8(N=34) ; 9(N=27)$

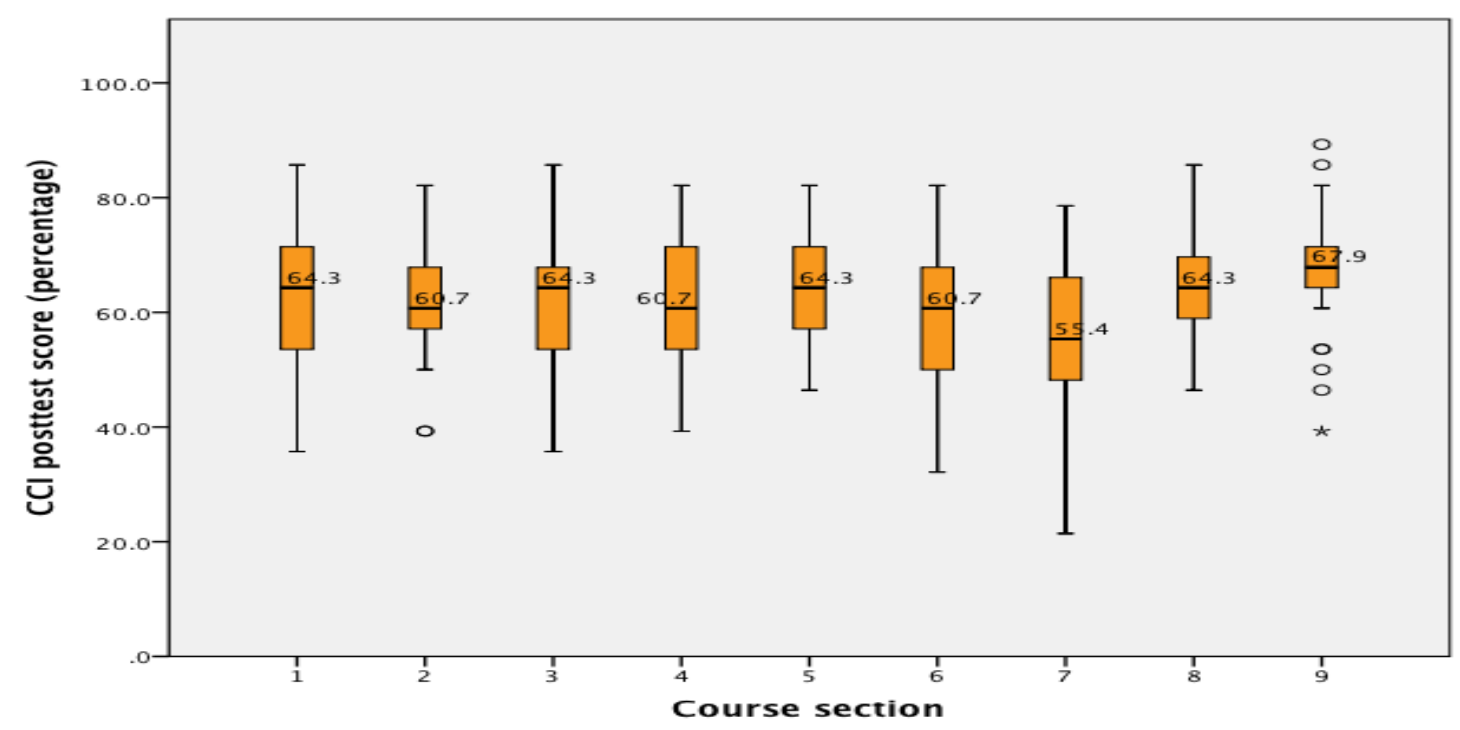

o and $*=$ outliers that are out of the ordinary value

\section{Circiuits Concept Inventory (pretest-posttest comparison)}

In this part of the analysis of CCI scores, we wanted to see how well students performed from pretest to posttest. In order to accomplish this, we needed to compare the students pretest 
scores to their posttest scores. Repeated measures ANOVA is a parametric test that can be used when comparing repeated measurements on samples to determine if the means differ ${ }^{18}$. As described in the Equivalent Group section, when the assumptions for using a parametric test are violated then a non-parametric statistical technique should be selected. We applied the Wilcoxon Signed-Ranks test to the pretest and posttest CCI scores. For more information about this test please see Reference 18. Table 2 summarizes the results of the Wilcoxon Signed-Ranks test.

Table 2. Results of the Wilcoxon Signed-Ranks test for CCI pretest-posttest by course section

\begin{tabular}{|c|c|c|c|c|c|c|}
\hline Section & $\begin{array}{c}\text { CCI Score } \\
\text { Pretest-Posttest }\end{array}$ & $\begin{array}{c}N \\
\text { (Ranks) }\end{array}$ & Mean Rank & Sum of Ranks & $Z$ & $p$ \\
\hline \multirow{3}{*}{1} & Negative Rank & 4 & 14.13 & 56.50 & \multirow{3}{*}{4.01} & \multirow{3}{*}{$<.001 *$} \\
\hline & Positive Rank & 29 & 17.40 & 504.50 & & \\
\hline & Equal & 5 & - & - & & \\
\hline \multirow{3}{*}{2} & Negative Rank & 0 & .00 & .00 & \multirow{3}{*}{4.02} & \multirow{3}{*}{$<.001 *$} \\
\hline & Positive Rank & 21 & 11.00 & 231.00 & & \\
\hline & Equal & 2 & - & - & & \\
\hline \multirow{3}{*}{3} & Negative Rank & 4 & 13.90 & 103.50 & \multirow{3}{*}{2.68} & \multirow{3}{*}{$.007 *$} \\
\hline & Positive Rank & 26 & 25.88 & 361.50 & & \\
\hline & Equal & 1 & - & - & & \\
\hline \multirow{3}{*}{4} & Negative Rank & 6 & 17.17 & 103.00 & \multirow{3}{*}{4.01} & \multirow{3}{*}{$<.001 *$} \\
\hline & Positive Rank & 33 & 20.52 & 677.00 & & \\
\hline & Equal & 1 & - & - & & \\
\hline \multirow{3}{*}{5} & Negative Rank & 9 & 26.89 & 242.00 & \multirow{3}{*}{1.43} & \multirow{3}{*}{.152} \\
\hline & Positive Rank & 27 & 15.70 & 424.00 & & \\
\hline & Equal & 0 & - & - & & \\
\hline \multirow{3}{*}{6} & Negative Rank & 10 & 21.25 & 212.50 & \multirow{3}{*}{1.90} & \multirow{3}{*}{.058} \\
\hline & Positive Rank & 26 & 17.44 & 453.50 & & \\
\hline & Equal & 3 & - & - & & \\
\hline \multirow{3}{*}{7} & Negative Rank & 4 & 9.38 & 37.50 & \multirow{3}{*}{1.86} & \multirow{3}{*}{.064} \\
\hline & Positive Rank & 13 & 8.88 & 115.50 & & \\
\hline & Equal & 1 & - & - & & \\
\hline \multirow{3}{*}{8} & Negative Rank & 5 & 16.30 & 81.50 & \multirow{3}{*}{3.56} & \multirow{3}{*}{$<.001 *$} \\
\hline & Positive Rank & 28 & 17.13 & 479.50 & & \\
\hline & Equal & 1 & - & - & & \\
\hline \multirow{3}{*}{9} & Negative Rank & 4 & 14.50 & 58.00 & \multirow{3}{*}{2.99} & \multirow{3}{*}{$.003 *$} \\
\hline & Positive Rank & 22 & 13.32 & 293.00 & & \\
\hline & Equal & 1 & - & - & & \\
\hline
\end{tabular}

*The difference is statistically significant.

As revealed in Table 2, there is a significant difference between the respective pretest and posttest scores for Section 1 ( $Z=4.01, p<.001, r=.65)$, Section 2 ( $Z=4.02, p<.001, r=.84)$, Section $3(Z=2.68, p=.007, r=.48)$, Section $4(Z=4.01, p<.001, r=.63)$, Section $8(Z=3.56, p<.001, r=.61)$, 
and Section $9(Z=2.99, p=.003, r=.58)$. For Sections $1,2,3,4,8$ and 9 , their respective positive sum of ranks scores were higher than their respective negative sum of ranks scores. Given the sum of ranks for each section's difference scores, the observed difference is in favor of positive ranks (posttest CCI scores). Using Cohen's criteria ${ }^{19-20}$ for interpreting the effect size ( $r=.10$, small; $r=.30$, medium; $r=.50$, large), the results suggested that the blended learning method significantly enhanced the conceptual understanding of circuits topics for students within each of these five sections. No statistically significant differences between respective pretest and posttest scores were observed for Sections 5, 6, and 7. It is interesting to note that the medians for all nine sections increased from pretest to posttest (see Figure 6).

Figure 6. CCI pretest-and posttest medians by course section, $1(N=38) ; 2(N=23) ; 3(N=31) ; 4(N=40) ; 5(N=36) ; 6(N=39) ; 7(N=18) ; 8(N=34) ; 9(N=27)$

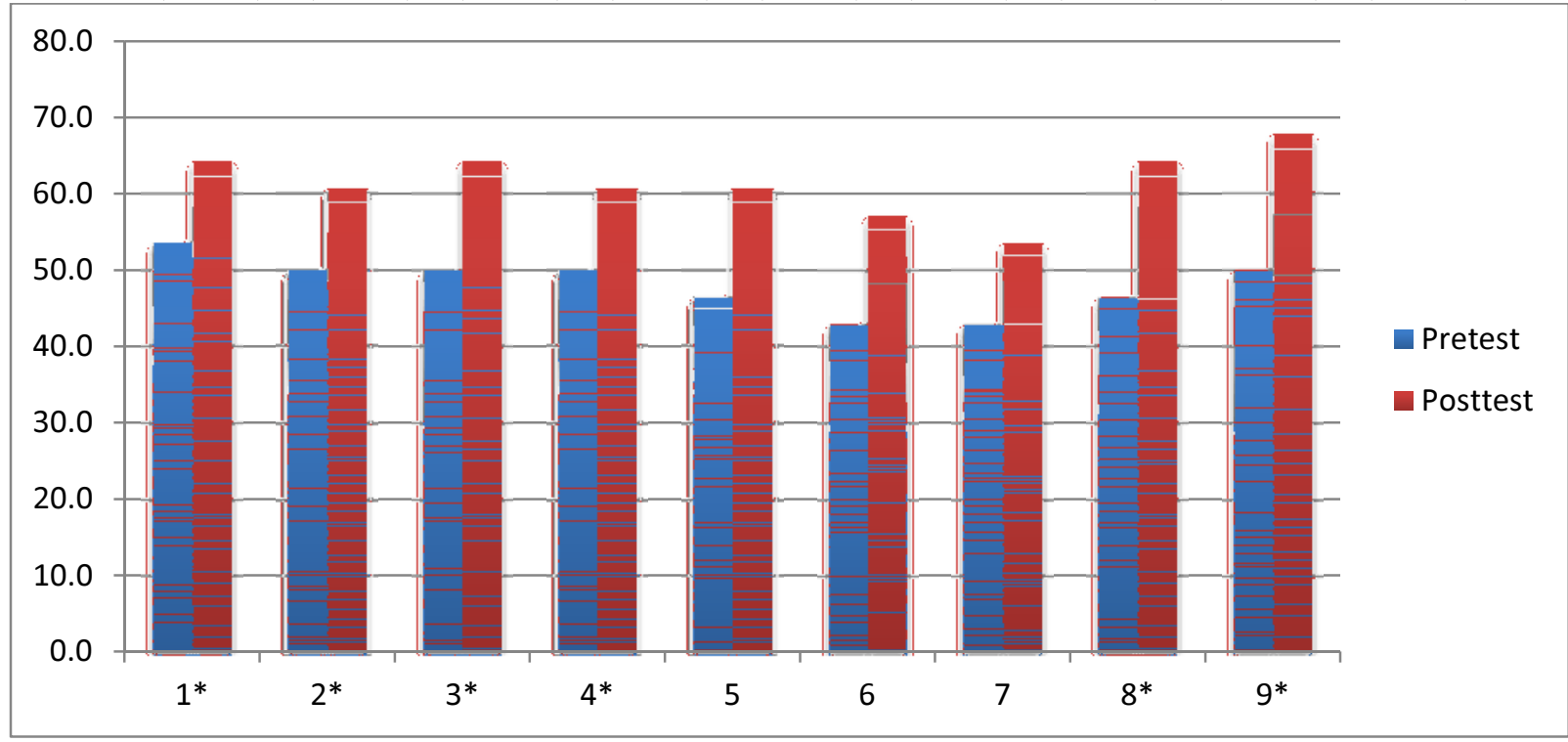

*=significant

\section{Summary}

This paper has presented an experiment where a very large enrollment course was blended using a MOOC platform. The course is challenging to teach in a traditional manner due to the breadth of the topics and due to the fact that it is viewed as a service course (required by non-majors), hence the motivation of students may be a factor in their learning. The MOOC provided an excellent learning management system to facilitate inverting the course. All of the lectures, homework assignments, and quizzes were online as part of the MOOC. The challenge with using a MOOC platform as opposed to stand-alone resources is that the MOOC must be a complete course in itself rather than just a collection of course resources. The findings indicate that the variation from section to section was lessoned by using the MOOC to invert the lectures portion of the course. Based on student and instructor feedback, modifications were made each time that the course was offered. The first term, the course was flipped with students doing homework during the lecture period, with the exception of the six mini-labs done during class. 
The second time it was taught, the instructors gave 10-15 minute summaries of the online lectures, allowed other time as recitation where students could ask questions based on the lectures or homework as well as work homework problems and do the mini-labs. The most recent time that it was taught, the offering was blended with class time spent on group-based worksheets, mini-labs, recitation, summary lectures, and a minor amount of time doing homework.

\section{Acknowledgement:}

This work was partially support by NSF TUES 1226065 . The authors would also like to thank the Center for $21^{\text {th }}$ Century Universities (C21U) at Georgia Tech for supporting the collaboration with the School of ECE at Georgia Tech.

\section{References}

${ }^{1}$ Droge, G. and Ferri, B. (2012) "Distributed Laboratories: Control System Experiments with LabVIEW and the LEGO NXT Platform," ASEE Annual Conference and Exposition, San Antonio, June 2012.

${ }^{2}$ Ferri, B. and Auerbach, J.,(2012) "A Portable Finite State Machine Module Experiment for InClass Use in Lecture-Based Course," ASEE Annual Conference and Exposition, San Antonio, June 2012.

${ }^{3}$ Breslow, L., Pritchard, D.E., DeBoer, J., Stump, G.S., Ho, A.D., and Seaton, D.T., (2013) "Studying Learning in the Worldwide Classroom Research into edX's First MOOC," Research and Practice in Assessment, Vol. 8, Summer 2013, pp. 13-25.

${ }^{4}$ Mitros, P.F., Afridi, K.K., Sussman, G.J., Terman, C.J., White, J.K., Fischer, L., and Agarwal, A. (2013). "Teaching Electronic Circuits Online: Lessons from MITx's 6.002x on edX," Proceedings of the IEEE International Symposium on Circuits and Systems (ISCAS), Beijing, China, May, 2013.

${ }^{5}$ Kolowich, S. (2014). "San Jose State U. Adopts More edX Content for Outsourcing Trial," The Chronicle of Higher Education, January 30, 2014.

${ }^{6}$ Margulieux, L. E., Bujak, K. R., McCracken, W. M., and Majerich, D. M. (2014, January). "Hybrid, Blended, Flipped, and Inverted: Defining Terms in a Two Dimensional Taxonomy." Proceedings of the $12^{\text {th }}$ Annual Hawaii International Conference on Education, Honolulu, HI, January 5-9.

${ }^{7}$ Allen, I.E., Seaman, J., and Garrett, R., 2007, "Blending In: The Extent and Promise of Blended Education in the United States, Sloan Consortium. Retrieved from http://sloanconsortium.org/publications/survey/blended06

${ }^{8}$ Bailey, J., Ellis, S., Schneider, C., and Vander Ark, T., 2013, "Blended Learning Implementation Guide," Digital Learning Now!, Version 1.0, February 2013. Retrieved from http://www.digitallearningnow.com/wp-content/uploads/2013/02/DLNSmartSeries-BLpaper_2012-02-05a.pdf 
${ }^{9}$ Papadopoulos, C., and Roman, A.S., 2010,'Implementing an Inverted Classroom Model in Engineering Statics: Initial Results," $117^{\text {th }}$ ASEE Annual Conference and Exposition, Louisville, KY, June $20-23$.

${ }^{10}$ Morin, B., Kecskemety, K., Harper, K.A., and Clingan, P.A., 2013, “The Inverted Classroom in a First-Year Engineering Course," $120^{\text {th }}$ ASEE Annual Conference and Exposition, Atlanta, GA, June 23-26.

${ }^{11}$ Mason, G., Shuman, T.R., and Cook, K.E., 2013, "Inverted (Flipping) ClassroomsAdvantages and Challenges," $120^{\text {th }}$ ASEE Annual Conference and Exposition, Atlanta, GA, June 23-26.

${ }^{12}$ Bishop, J.L., and Verleger, M.A., 2013,"The Flipped Classroom: A Survey of the Research," $120^{\text {th }}$ ASEE Annual Conference and Exposition, Atlanta, GA, June 23-26.

${ }^{13}$ Day, J.A., Foley, J.D., 2006, "Evaluating a Web Lecture Intervention in a Human-Computer Interaction Course," IEEE Transactions on Education, 49(4):420-431.

${ }^{14}$ Helgeland, B., \& Rancour, D. (2013). Circuits Concept Inventory. Retrieved from http://www.foundationcoalition.org/home/keycomponents/concept/circuits.html

${ }^{15}$ Knoke, D., Bohrnstedt, G. W., and Mee, A. P., 2002, "Statistics for Social Data Analysis," Belmont, CA: Wadsworth/Thompson Publishing.

${ }^{16}$ Onwuegbuzie, A. J., \& Daniel, L. G., 2002. "Uses and Misuses of the Correlation Coefficient". Research in the Schools, 9(1): 73-90.

${ }^{17}$ Cardinal, R. N., and Aitken, M. R. F. (2006) ANOVA for the Behavioural Sciences Research. Mahwah, NJ: Erlbaum Press.

${ }^{18}$ Sheskin D. J. 2011., Handbook of Parametric and Nonparametric Statistical Procedures, 5th ed. Boca Raton: Chapman \& Hall /CRC.

${ }^{19}$ Cohen, J. (1988). Statistical Power Analysis for the Behavioral Sciences, $2^{\text {nd }}$ ed. Hillsdale, NJ: Lawrence Erlbaum.

${ }^{20}$ Cohen, J. (1992). A Power Primer. Psychological Bulletin, 112(1), 155-159. 